\title{
Heterogeneidade entre Leitores Julgados Competentes pelas Professoras
}

\author{
Angela Maria Vieira Pinheiro ${ }^{1}$ \\ Universidade Federal de Minas Gerais
}

\begin{abstract}
Resumo
O desempenho de leitura de um grupo de crianças de quarta série, julgadas pela professora como leitoras com desenvolvimento normal, foi investigado. Uma medida de desempenho deficiente/competente - baixos níveis de erros e tempos de reação rápidos para as respostas corretas para a leitura em voz alta de palavras reais (variando em familiaridade, regularidade e comprimento) e não-palaras (com a mesma estrutura ortográfica das palavras reais e variando em comprimento) - foi obtida com o objetivo de estabelecer uma definição de desempenho eficiente de leitura que, por sua vez, serviu de base para a identificação de deficiências, em crianças do mesmo grupo, cujos resultados situaram-se fora da amplitude estabelecida como normal. Dentre esses participantes houve um exemplo de dislexia fonológica e vários casos apresentando danos que afetaram ambos os processos, lexical e fonológico, com uma tendência para o padrão fonológico. A discrepância entre a avaliação da professora e a avaliação cognitiva de leitura conduzida é discutida.

Palavras-chave: Desempenho eficiente de leitura; dislexia.
\end{abstract}

Heterogeneity among Readers Judged as Competent by the Teacher

\begin{abstract}
The reading performance of a group of fourth graders, judged by the teacher, as having normal development was investigated. A measure of efficient performance - low error rates and fast vocal reaction-times for correct responses to words (of varying familiarity, regularity and length) and non-words (formed with the same orthographic structure and length of the words) - was obtained and used as a basis for the identification of inefficiencies among the subjects whose results were outside the main range. Within these subjects there was an example of phonological dyslexia and many cases presenting impairments affecting both lexical and non-lexical processes with a bias to the phonological pattern. The discrepancy between the assessment of the teacher and the cognitive assessment conducted is discussed.

Keywords: Efficient reading performance; dyslexia.
\end{abstract}

A área denominada Reconhecimento de Palavras é a outra abordagem experimental - além do estudo de palavras em combinação -, para a análise dos processos envolvidos na leitura adotada pela psicologia cognitiva. A manipulação de palavras isoladas com propriedades lingüísticas contrastantes (p. ex.: palavras familiares/nãofamiliares) tem propiciado não só a formulação de modelos de processamento da leitura (e da escrita), como também o desenvolvimento de procedimentos para avaliar os componentes desses modelos. Com base nessa teoria e no uso dos métodos da psicologia cognitiva experimental, Seymour, em várias publicações (Seymour, 1986, 1987; Seymour \& MacGregor, 1984), desenvolveu um método para a investigação dos processos básicos de leitura, que recebeu a denominação de Procedimento de Avaliação Cognitiva. Esse método, que é apropriado para a avaliação, tanto das desordens de leitura adquiridas como das de desenvolvimento de falantes de inglês e de

\footnotetext{
${ }^{1}$ Endereço para correspondência: R. Monte Carmelo, 34/101, 31015-230, Belo Horizonte, Minas Gerais. Fone: (31) 34412284, Fax: (31) 4995027. Email:apinheiro@pobox.com
}

português (p. ex.: Pinheiro, 1994, 1995a, 1999; Pinheiro \& Parente, 1999), atualmente constitui referência para a construção de conjuntos semelhantes de procedimentos em diferentes línguas alfabéticas. Envolve o uso de um modelo de processamento de informação das funções básicas de leitura e procedimentos experimentais que testam os componentes do modelo, de forma a determinar as partes do sistema que estão danificadas (dislexia adquirida) ou que não se desenvolveram adequadamente (dislexia do desenvolvimento) e também analisar as funções restantes de leitura que foram preservadas.

A pesquisa a ser descrita relata a aplicação das tarefas de leitura em voz alta de palavras reais e de não-palavras, conforme Procedimento de Avaliação Cognitiva de Leitura de Seymour, a uma amostra de crianças brasileiras com desempenho de leitura julgado eficiente pelas professoras. Tem como objetivo o estabelecimento de uma definição de desempenho eficiente de leitura tomado como a habilidade de ler em voz alta e de mostrar compreensão do material escrito - e a identificação de deficiências que podem co-existir com a leitura competente (os termos leitura competente/sujeitos 
competentes e leitura eficiente/sujeitos eficientes são usados aqui como equivalentes).

\section{O Modelo de Processamento de Informação e o Procedimento Experimental para Testar os seus Componentes}

Um dos modelos derivados da teoria de duplo processo de Morton (1979), que se tem mostrado muito útil, é o desenvolvido por Ellis e Young (1988) cuja adaptação por Pinheiro (1995b) é apresentada na Figura 1. Segundo esse modelo, a pronúncia e a obtenção de significado da escrita podem ocorrer por meio de processos visuais/lexicais ou por um processo envolvendo decodificação fonológica - processo fonológico.

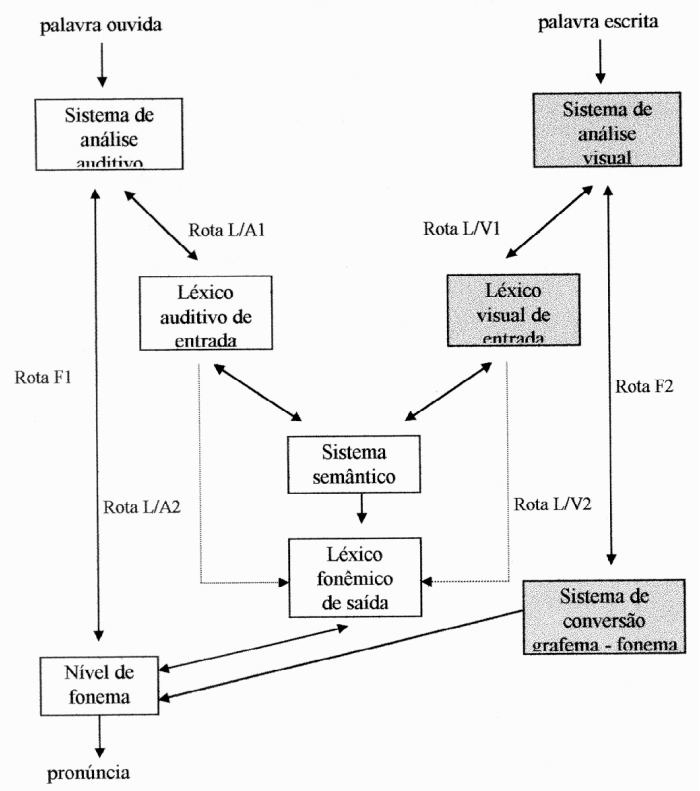

Figura 1. Modelo de reconhecimento visual e fonológico de compreensão e de pronúncia de palavras isoladas, adaptado de Ellis e Young (1988). A seguinte denominação de rotas foi aqui introduzida: (a) processamento de palavras ouvidas: L/A1 - rota léxico-semântica auditiva, L/A2 - ligação direta entre o léxico auditivo de entrada e o de saída e F1 - rota fonológica; (b) processamento de palavras escritas: L/V1 - rota léxico-semântica visual, L/V2 - ligação direta entre o léxico visual de entrada e o de saída e F2 - rota fonológica.

O sistema de análise visual, o léxico visual de entrada e o sistema de conversão grafema-fonema são os componentes específicos para a leitura. Esses sistemas consistem em procedimentos para a análise visual da escrita, reconhecimento de palavras e de grafemas e também de processos que transmitem a informação, do nível visual para os processos centrais relacionados com significado, produção da fala, ou síntese de fonemas (discutiremos aqui principalmente os componentes do modelo usados no processamento de palavras escritas. Para detalhes sobre o processamento de palavras faladas, parte esquerda da Figura 1, vide Ellis \& Young, 1988, ou Pinheiro, 1994, 1995b).

O sistema semântico, o léxico fonêmico de saída e o nível de fonema são componentes comuns ao processamento da fala e da leitura. O primeiro sistema representa conceitos, contém funções para a avaliação e comparação de significados, e seu output controla a produção da fala pela via do léxico fonêmico de saída. Este último sistema é visto como o armazenador das pronúncias das palavras que são transmitidas ao mecanismo articulatório, passando pelo nível de fonema que, por sua vez, tem como papel a recuperação e agrupamento dos fonemas para a produção da pronúncia.

No que se refere aos métodos de estudo, o lado lexical da leitura tem sido investigado pelo desempenho em tarefas de leitura em voz alta de palavras reais - variando em freqüência de ocorrência, regularidade letra-som e número de letras/sílabas - enquanto o lado fonológico tem sido definido em termos da habilidade de ler nãopalavras (seqüência de letras ortograficamente plausíveis e pronunciáveis, mas sem nenhum significado) formadas com a mesma estrutura ortográfica e comprimento das palavras reais. A medida de tempo de reação para as respostas corretas e as porcentagens de erros resultantes da leitura desses estímulos têm sido estudadas em amostras de sujeitos ou em descrições de casos individuais. A leitura de palavras reais é um teste da rota lexical, e a de nãopalavras um teste do processo fonológico.

Considerando o tempo de processamento, Seymour (1986) toma a forma da distribuição do tempo de reação como um importante índice da eficiência dos processos lexicais e fonológicos. O formato de uma distribuição pode mostrar padrões esperados para a leitura de palavras reais e de não-palavras: (1) tipo A - distribuição com uma alta preponderância de tempos de reação rápidos (abaixo de $2000 \mathrm{mseg}$ ), não contendo respostas lentas ou dispersas; (2) tipo B - distribuição com preponderância de tempos rápidos combinados com uma cauda de respostas lentas mais ou menos considerável; e, (3) tipo C - distribuição amplamente dispersa em toda a amplitude da escala de tempos de reação (0-6000 mseg). Os padrões A, B e C são indicativos de processos eficientes, parcialmente eficientes e ineficazes, respectivamente.

\section{Leitura de Palavras Reais}

\section{Processamento Léxico-Semântico e Fonológico}

Após ser a palavra analisada pelo sistema de análise visual e reconhecida no léxico visual de entrada (em que estão armazenadas as representações ortográficas das palavras), o seu significado é recuperado do sistema 
semântico, e sua pronúncia, do léxico fonêmico de saída (onde as formas faladas das palavras são arquivadas como um todo). Este é o processo léxico-semântico. Por outro lado, a leitura pelo processo fonológico depende da utilização do conhecimento das regras de conversão grafema-fonema para construir-se a pronúncia da palavra lida - processo de decodificação fonológica (rotas L/V1 e F2 respectivamente na Figura 1). O código fonológico construído é identificado pelo sistema de análise auditiva, reconhecido pelo léxico auditivo de entrada (onde as representações auditivas das palavras são arquivadas) e o significado da palavra (arquivado no sistema semântico) é liberado como se ela tivesse sido ouvida. Então, na leitura fonológica, o acesso ao significado - ao contrário do que ocorre no processo léxico-semântico - dá-se posteriormente à construção da pronúncia e pela intermediação da forma auditiva da palavra.

Também na forma em que o significado é acessado reside a outra principal diferença entre o processo léxicosemântico e o fonológico para o processamento de palavras reais, além da forma de chegar-se à sua pronúncia (por meio do endereçamento da pronúncia arquivada no léxico fonêmico de saída, no primeiro processo, e de sua construção a partir do sistema de correspondência letra-som no processo fonológico). Palavras com grafias diferentes, mas com o mesmo som (homônimos heterográficos, tais como o par concerto/conserto), quando lidas pelo processo fonológico, estão sujeitas a erros de troca de significado. Para a representação fonológica de pares de homônimos heterográficos, existem, no sistema semântico, duas representações semânticas e o leitor pode recuperar um significado de uma ou outra representação. Provavelmente, ele se inclinará para um significado mais familiar ou mais freqüente. $\mathrm{Na}$ leitura pelo processo léxico-semântico, ao contrário, o acesso ao significado é feito com base na grafia da palavra. Tomando o par de exemplos acima, para a palavra concerto, existe, no sistema semântico, apenas um significado. O mesmo é verdade para conserto.

No Procedimento de Avaliação Cognitiva de Leitura de Seymour $(1986,1987)$, o funcionamento do sistema semântico é avaliado por meio de tarefas de decisão semântica em que o nome de uma categoria (p. ex.: roupa, fruta ou corpo) é apresentado na tela de um computador seguido pela apresentação de uma palavra. $\mathrm{O}$ participante é instruído a apertar a tecla designada Sim se a segunda palavra é parte da categoria da palavra apresentada anteriormente. Caso contrário, deve apertar a tecla designada Não.

\section{Processamento Léxico-Fonêmico}

Existe ainda uma segunda possibilidade de leitura lexical de palavras (e, ocasionalmente, de não-palavras) que se processa por meio de uma conexão direta entre $\mathrm{o}$ léxico visual de entrada e o léxico fonêmico de saída, o que constitui o processo léxico-fonêmico (rota L/V2 na Figura 1). A tarefa de leitura de palavras reais em voz alta é empregada como um procedimento para testar esse processo. Nesse tipo de leitura, a recuperação da pronúncia pode ser assistida por concomitante processamento semântico ou por concomitante conversão grafema-fonema. Diferentemente da rota fonológica, ambas as rotas L/V1 e L/V2 processam as palavras irregulares (palavras contendo correspondência letra-som não explicadas por regras) com sucesso (assim como as regulares), pois sua pronúncia é recuperada como um todo, do léxico fonêmico de saída.

A implicação da diferença em acessar a pronúncia entre os processos lexicais e o fonológico refere-se à forma como as palavras irregulares são pronunciadas. Por exemplo, a palavra irregular fixo só será lida corretamente se sua pronúncia for retirada como um todo do léxico fonêmico de saída que, como vimos, arquiva a pronúncia das palavras reconhecidas pelo léxico visual de entrada. Se esse estímulo, ao contrário, for processado pela rota fonológica, será, portanto, regularizado, isto é, será lido como $<$ ficho $>$ e não como $<$ fikso $>$. Isso ocorre porque o processamento fonológico opera-se por meio da aplicação de regras de conversão grafema-fonema nas unidades sub-lexicais, o que não funciona quando a palavra lida possui correspondência irregular.

Além do envolvimento do processo de conversão grafema-fonema na recuperação da pronúncia de palavras reais, outros fatores geralmente manipulados na tarefa de leitura em voz alta têm a finalidade de oferecer as seguintes informações sobre as palavras: (1) efeitos de variação do número de letras; (2) efeitos de variação dos níveis de familiaridade; e, (3) o envolvimento do processo semântico.

A variação do fator comprimento de palavras reais refere-se ao efeito de comprimento: maior freqüência de erros e de tempo de reação elevado na leitura de palavras longas em relação a palavras mais curtas. Algumas teorias de reconhecimento de palavras propõem que as palavras sejam analisadas com um todo, aproximandose de um processamento paralelo. Assim, espera-se na leitura desses estímulos um efeito de comprimento pequeno ou inexistente. Quando o efeito é mais acentuado do que se espera, indica que a leitura está sendo feita pela 
rota fonológica, em que a pronúncia é construída de forma serial por decodificação.

O efeito de variações nos níveis de familiaridade de palavras - fator freqüência de ocorrência de palavras pode dar-se no nível de reconhecimento (no léxico visual de entrada) ou na operação de recuperação lexical da pronúncia (léxico fonêmico de saída). As palavras de alta freqüência - por requererem menor ativação - tendem a ser reconhecidas mais rapidamente e/ou mais corretamente do que aquelas com baixa ocorrência palavras de baixa freqüência. Essa vantagem em termos de processamento, para o primeiro tipo de palavras, é conhecida como efeito de freqüência. Assim a ocorrência desse efeito é interpretada como uma indicação do envolvimento do processo lexical na leitura, enquanto um efeito de freqüencia exagerado (maior do que normalmente encontrado) indica um nível de disfuncionamento do processo lexical.

O envolvimento do processo semântico na recuperação da pronúncia e na produção de uma palavra tem sido testado por meio da manipulação dos fatores concretude e classe gramatical. Presume-se que os efeitos de concretude - melhor leitura de palavras concretas em relação a palavras abstratas - e de classe gramatical melhor leitura de certas classes gramaticais (p. ex.: substantivos) do que outras (p. ex.: preposições, conjunções) - indicam que houve processamento semântico em suporte à recuperação da pronúncia ou produção da grafia. Por outro lado, como vimos, a variação do fator regularidade grafema-fonema tem demonstrado que o processamento pela rota fonológica é afetado adversamente pela regularidade do estímulo. Em português, a maioria das palavras irregulares apresentam implicações somente para a escrita, já que podem ser pronunciadas de acordo com o uso das regras de correspondência letra-som. A exceção, para a leitura, são as palavras $\operatorname{com} x$ entre vogais e as palavras contendo as vogais $o$ e $e$ em posição tônica em palavras paroxítonas. Em ambos os casos as variações em pronúncia não são controladas por regras. Enquanto o $x$ em posição intervocálica pode valer /S, z, s, ks/ ou /O/ como em vexame, exame, trouxe, táxi e exceto, respectivamente, as vogais $o$ e $e$ no contexto citado podem ser pronunciadas de forma aberta /E/ e / «/ (p. ex.: bola, pele) ou fechada /o/ e /e/ (p. ex.: bolo, dele). Por essa razão o efeito de regularidade não é esperado na leitura, pelo menos na leitura das crianças mais experientes, por terem domínio mais amplo dessas regras.

As palavras reais podem, pois, ser lidas por meio de dois processos lexicais e um processo fonológico. No entanto, as palavras irregulares, quando lidas pelo processo fonológico podem ter sua pronúncia regularizada, como dissemos, ou ser lidas com um aumento de tempo de reação. Esse aumento ocorre porque há um conflito entre a pronúncia correta resultante do processamento lexical e a pronúncia regularizada, derivada da decodificação fonológica.

\section{Leitura de Não-Palavras}

O processamento de não-palavras que, por definição, não têm entradas no léxico visual de entrada, dá-se pela rota fonológica. A identidade dos grafemas é transmitida do sistema de análise visual para o sistema de conversão grafema-fonema, e desse sistema para o nível de fonema, onde os elementos fonêmicos podem ser recuperados e agrupados para formar a pronúncia.

Nos experimentos de leitura de não-palavras, as nãopalavras são construídas com a mesma estrutura ortográfica e mesmo comprimento das palavras reais (um outro fator que pode ser controlado nesses experimentos refere-se à pronúncia de não-palavras que soam como palavras reais (p. ex.: táquissi que soa como táxi) ou daquelas que não soam com tais (p. ex.: sali) - efeito de homofonia). O contraste entre o desempenho na leitura de palavras reais e de não-palavras é conhecido como efeito de lexicalidade. Espera-se que as palavras reais sejam lidas mais rapidamente e mais corretamente do que as não-palavras. Assim como o efeito de freqüência, o efeito de lexicalidade é também um indicativo de leitura lexical. Embora as palavras reais possam ser lidas pela rota fonológica, na leitura eficiente elas são lidas pela rota lexical por meio da ativação de suas representações ortográficas, semânticas e fonológicas, pré-estocadas no léxico. Esse processo é muito mais rápido e eficiente do que o de decodificação grafema-fonema, usado para a leitura de palavras desconhecidas e de não-palavras. No entanto, um forte efeito de lexicalidade, ou seja, leitura de não-palavras bem mais lenta do que a de palavras reais, indica uma deficiência no processo fonológico.

Com relação à variação do número de letras nas nãopalavras - efeito de comprimento -, espera-se que esse efeito seja maior para as não-palavras do que para as palavras reais. Ao contrário dos últimos estímulos, a pronúncia das não-palavras é construída segmento a segmento, por decodificação fonológica, o que gera aumento do tempo do processamento assim como maior possibilidade de erros quanto maior o número de letras do item.

Para concluir, a análise dos efeitos das características lingüísticas dos estímulos na leitura em voz alta - em termos de tempo de reação e/ou em níveis de erros está relacionada com as propriedades das vias léxicofonêmica e fonológica, podendo apresentar indícios do 
processo utilizado. Enquanto o efeito de freqüência, de concretude e o de lexicalidade indicam leitura lexical, os efeitos de regularidade e de comprimento indicam leitura fonológica.

Outra fonte de averiguação do processo de leitura usado refere-se à análise de erros. Podem-se distinguir dois tipos principais de erros: recusas e substituições (substituições de estímulos alvos, tanto em resposta a palavras reais como a não-palavras). Presume-se que a análise desses erros ofereça uma indicação de suas possíveis origens dentro do sistema de processamento. Assim, uma resposta que é uma palavra real (p. ex.: resposta onça para o alvo ouça) é, de acordo com essa teoria, um indício do uso do processo lexical, já que o output do léxico fonêmico de saída consiste exclusivamente em palavras reais. Erros desse tipo são conhecidos como lexicalizações, mas aqui serão denominados respostas-palavras. As respostas que geram uma não-palavra - aqui denominadas respostas-não-palavras (p. ex.: resposta capra para o alvo cobra) são produzidas quando o sistema grafema-fonema é usado. Esses erros podem ocorrer como resultado de uma simples troca de vogal e/ou consoante ou de uma regularização de um estímulo que contém uma correspondência letra-som irregular (p. ex.: o estímulo boxe pronunciado como boche). Isto significa que um alto índice de respostas-palavras é indicativo do uso de processo lexical, enquanto um alto índice de respostas-não-palavras denota, por outro lado, o uso do processo fonológico.

\section{Leitura Competente e Dislexia do Desenvolvimento}

Seymour (1986) propôs um método que combina estudo de casos com amostras de sujeitos (o primeiro, derivado da neuropsicologia cognitiva e o segundo, da psicologia cognitiva), no qual todos os sujeitos passam por uma avaliação cognitiva da leitura. Esse método tem a vantagem de oferecer uma descrição detalhada e sensível de casos individuais e ao mesmo tempo prover dados representativos da natureza da heterogeneidade na população de disléxicos. Usando essa metodologia, Seymour $(1986,1987)$ distinguiu o desempenho de leitores competentes daqueles com dificuldade e, além de confirmar a existência de heterogeneidade entre os leitores com disfunção, concluiu que os grupos de leitores normais são também internamente heterogêneos e, por causa disso, devem ser analisados como séries de casos individuais.

Essa descoberta está fundamentalmente em contraste com a pressuposição prevalecente na psicologia cognitiva, de que a leitura normal (em cada um de seus níveis de desenvolvimento), e a que apresenta disfuncionamento, são condições unitárias. Seymour (1986) refere-se a esse

Psicologia: Reflexão e Crítica, 2001, 14(3), pp. 537-551 ponto de vista e à metodologia a ele associada comparação de grupos de leitores com disfunções e grupo de leitores normais com semelhante idade e nível de competência - como pressuposição em favor da homogeneidade a qual, por sua vez, está em contraposição com a metodologia de estudo de caso adotada pela neuropsicologia cognitiva, em que os dados de um número selecionado de pacientes lesados são usados para ilustrar as várias possibilidades de danos cognitivos.

Diante da possibilidade de diferenças teóricas significativas junto às crianças com dislexia do desenvolvimento, Seymour (1986) adverte que ambas, a metodologia que se baseia em comparações entre grupos, e a de estudo de casos individuais, se usadas sozinhas, devem ser de utilidade limitada para o entendimento dos processos de leitura. A primeira metodologia não é satisfatória porque descarta a evidência de variação, e a segunda porque não oferece informação sobre as propriedades gerais e sobre a distribuição de padrões recorrentes. Como alternativa sugere uma metodologia baseada no que chama pressuposição em favor da heterogeneidade, que combina a investigação cognitiva de casos isolados com uma abordagem não seletiva para a amostragem de sujeitos. O resultado desse procedimento, que foi adotado nos estudos de 1986 e 1987, foi a identificação e a descrição das características do processamento individual que tanto os leitores normais como os disléxicos devem possuir.

Nesses estudos, a competência de leitura foi avaliada pelo Schonell Grade Word Test (Schonell \& Schonell, 1956) - um teste padronizado para a leitura de listas de palavras isoladas. Uma vez que esse teste é, primeiramente, uma medida da eficiência do processo lexical, pode-se antecipar que o desempenho competente nessa medida é indicativo de funcionamento eficiente da rota lexical e vice-versa. Seymour $(1986,1987)$ confirmou essa expectativa e concluiu que a rota lexical desempenha um papel central na obtenção da competência em leitura. Como já mencionado, a eficiência dessa rota é indexada pelas taxas de erros e pela distribuição de tempos de reação para as pronúncias corretas de palavras reais de diferentes níveis de familiaridade (palavras de alta e baixa freqüência de ocorrência). Distribuições bem formadas são indícios de processos eficientes, e distribuições contendo proporções elevadas de respostas vagarosas indicam um declínio na eficiência, que pode variar desde disfunção severa - predominância de respostas vagarosas (especialmente para os itens de baixa freqüência) - até disfunção extrema - quase nenhuma resposta rápida. Seymour (1987) enfatiza que embora o limite do que deve ser considerado leitura lexical eficiente não tenha sido ainda 
estabelecido, existem indícios de que uma pequena perda de eficiência dessa rota (na forma de ocasionais respostas lentas) é tolerável, e que a leitura competente pode ser conseguida, a despeito de considerável ineficiência em sistemas adjacentes, tais como o sistema visual e o processo de conversão grafema-fonema.

Considerando o desempenho dos leitores com disfunção, Seymour (1987) demonstrou que deficiências na rota lexical são sempre acompanhadas de deficiências no processo fonológico, e que a extensão do disfuncionamento nos dois processos variava. A ineficiência podia, também, ser acompanhada de funcionamento eficiente em um ou mais domínios do modelo de processamento, tais como o sistema de análise visual e/ou sistema semântico (testados através de tarefas de decisão visual - comparação de letras que aparecem em fileiras - ou semântica - a identificação de atributos comuns em palavras apresentadas ao mesmo tempo - por meio de um toque de teclas designadas Sim e Não). Tomando a extensão do dano como referência, Seymour (1987) distinguiu dois subtipos principais de inabilidade, o fonológico e morfêmico, e atribuiu a esses subtipos definições operacionais que aperfeiçoa em 1994: (1) dislexia fonológica - a taxa de erros para a leitura de não-palavras é substancialmente mais alta do que a taxa para palavras reais de estruturas comparáveis, e o tempo de reação deve ser rápido para ambas, as palavras reais e não-palavras (mas acompanhado de muitos erros nas não-palavras) ou deve ser rápido para as palavras reais, mas lento e laborioso para as não-palavras, produzindo padrões claramente discrepantes; (2) dislexia morfêmica - aumento da taxa de erros na leitura de palavras reais, especialmente nos itens de baixa freqüência, forte efeito de regularidade, alguns erros de regularização, semelhantes níveis de erros e/ou de TR na leitura de palavras reais e não-palavras e forte efeito de comprimento no tempo de reação. A dislexia fonológica resulta de um disfuncionamento primário do processo de conversão grafema-fonema, e a morfêmica, de um disfuncionamento primário do processo de reconhecimento de palavras que é o equivalente, na dislexia do desenvolvimento, da dislexia de superfície adquirida. $\mathrm{O}$ termo dislexia morfêmica foi escolhido por Seymour e MacGregor (1984) para salientar que essa condição reflete uma disfunção dos processos de identificação de morfemas (a unidade de processamento da rota lexical, segundo evidências).

\section{Método}

\section{Amostra}

A amostra foi constituída pelos sujeitos mais velhos do estudo de Pinheiro (1995a) - um grupo de 20 crianças, com média de idade de dez anos e oito meses, cursando a quarta série do primeiro grau de uma escola particular de classe média de Belo Horizonte e julgadas como boas leitoras pela professora. O julgamento da professora foi feito com base na seguinte solicitação da pesquisadora: "Gostaria que, dentre seus alunos, escolhesse aqueles que considera estarem tendo um desenvolvimento normal na leitura para se submeterem a uma avaliação dessa habilidade. $\mathrm{Na}$ sua escolha, por favor, elimine tanto os alunos extremamente bons na leitura, como aqueles que apresentam dificuldades". A única forma de controle possível do grau de subjetividade do professor no julgamento de competência foi a padronização da instrução. De acordo com as escalas padronizadas de inteligência não-verbal Matrizes Progressivas de Raven - os níveis de inteligência da amostra variaram de inteligência média a acima da média.

\section{Procedimento e Instrumento}

A avaliação de leitura, aplicada por meio de um microcomputador, limitou-se ao teste dos processos léxico-fonêmico e fonológico. Baseou-se, pois, na de leitura em voz alta de uma lista de 96 palavras reais que variavam em freqüência de ocorrência, em regularidade de correspondência entre som-letra e em comprimento, juntamente com uma lista de 96 não-palavras. Trata-se da mesma prova utilizada por Pinheiro (1994, 1995a) em um estudo sobre o desenvolvimento dos processos lexicais e do fonológico, na leitura e na escrita. Usando uma adaptação desse instrumento, Capovilla, Capovilla e Macedo (1998) replicaram os resultados de Pinheiro em uma amostra de crianças paulistas. Em todos esses estudos o envolvimento do processo semântico na leitura em voz alta não foi testado. Seymour (1986) descobriu que os sujeitos, em geral, não foram afetados pela variável classe de palavras. Constatou também pouca evidência de efeitos de significado abstrato. Diante desses resultados, concluiu que a incidência de efeitos semânticos em uma amostra de leitores competentes parece variável: afeta a leitura de uns, mas não de outros.

As listas de palavras reais foram organizadas com base em uma análise de regularidade som-letra da ortografia do português brasileiro (Pinheiro, 1994, 1995a) e em uma investigação da freqüência de ocorrência de palavras em livros de leitura da escola primária - o que levou à classificação de palavras nas categorias de alta freqüência e de baixa freqüência de ocorrência (Pinheiro \& Keys, 1987). A análise de regularidade, que considerou a relação som-letra (direção da escrita), gerou três categorias de palavras: regular [cada som corresponde a apenas uma letra (p. ex.: festa, porta)], regra (a correspondência é regulada por regras contextuais (p. ex.: gato, coisas)) e irregular (a correspondência é ambígua e, portanto, não 
explicada por regras (p. ex.: hino, xerife)) que foram igualmente distribuídas em cada nível de freqüência, que por sua vez era formado de 48 palavras. As não-palavras foram formadas com a mesma estrutura ortográfica e comprimento (quatro-sete letras) das palavras reais. Mantiveram as correspondências regular, regra e irregular das palavras das quais elas foram derivadas. Por exemplo, o estímulo dasa derivado de casa, como o próprio estímulo casa, foi classificado como regra. Da mesma forma ecute, derivado da palavra irregular açude foi tomado como irregular. Os sujeitos foram testados, individualmente, em duas sessões. As respostas eram classificadas pelo experimentador como corretas, incorretas ou recusas durante o experimento. As respostas incorretas eram digitadas após sua ocorrência e o percentual dessas respostas foi usado na análise quantitativa. Os erros foram também analisados em termos qualitativos segundo a classificação abaixo.

\section{Análise Qualitativa dos Erros}

Tomando o percentual obtido na análise quantitativa de erros, distinguiu-se o percentual de erros que geraram palavras reais (p. ex.: a palavra extenso lida como exceto e a não-palavra saliz como saliva) e o percentual dos que geraram não-palavras. O primeiro tipo de erro foi denominado resposta-palavra (resposta(s)-PR(s)) e o segundo, resposta-não-palavra (resposta(s)-NP(s)). As respostas-NPs resultaram dos seguintes erros:

(1) regularização fonética: a pronúncia de uma correspondência irregular com uma correspondência regular em um contexto específico (p. ex.: boxe /'bokse/ pronunciada como boche /'boSe/);

(2) erro de acentuação tônica: o acento tônico é deslocado (p. ex.: cabrás por cabras) e vidacas por vídacas);

(3) mudança de qualidade das vogais: uma vogal aberta é pronunciada como fechada e vice-versa (exemplo: pêço por peço e dalê por dalê);

(4) falha na tradução: respostas que contêm pequenos erros de identificação de letra ou posição (confusão entre consoantes vocalizadas - sonoras - e não-vocalizadas surdas - e entre consoantes com formas similares, troca de vogal e adição ou subtração de sílabas, nasais e consoantes pós-vocálicas - r, s, lou n) e

(5) contextual: falha ao levar em consideração as regras contextuais - o estímulo coisas lido como coissas e dasa lido como dassa).

Nessa análise, ao contrário da análise quantitativa (em que as respostas foram classificadas como acerto ou erro), foi feito o levantamento do número de erros por item. Assim, nas respostas-NPs, o número total de erros por item era o resultado da soma de cada um dos erros cometidos.

\section{Resultados}

Os resultados consistiram na medida de tempo de reação (TR) para as respostas corretas e de percentagens de erros obtidos na leitura de palavras reais e de nãopalavras, separadamente. As análises estatísticas, realizadas com base no nível individual, consistiram na procura de efeitos de freqüência, de regularidade e de comprimento em resposta a palavras reais e na procura do efeito de comprimento em resposta a não-palavra. As comparações entre palavras de baixa freqüência e não-palavras testavam o efeito de lexicalidade. Todas as análises foram realizadas com base nos tempos de reação e nas porcentagens de erros, exceto para o efeito de comprimento, cujas análises limitaram-se ao tempo de processamento. Os TRs foram comparados por teste $t$ e as porcentagens de erros por Chi quadrados. Independentemente do tipo e do número de erros cometidos em um mesmo item, somente um erro foi marcado para aquele item.

O efeito de comprimento foi obtido relacionando o tempo de reação ao comprimento de palavras e nãopalavras, com a finalidade de descobrir a taxa de processamento para cada letra que compõe o estímulo, em milésimo de segundos. Essa medida - a inclinação da regressão (o aumento do tempo reação para cada letra individual de um estímulo) - é útil na averiguação do modo de operação - serial ou paralelo - tanto do léxico visual de entrada como do processo de conversão grafema-fonema. A linearidade da relação entre tempo de reação e comprimento de palavras e não-palavras foi calculada pela aplicação do teste $F$ (devido a restrições de espaço, os resultados do controle da variável comprimento para palavras reais e para não-palavras serão apresentados e discutidos apenas parcialmente (vide Pinheiro, 1999, onde esses resultados são apresentados mais detalhadamente)).

\section{Resultados Gerais}

Tomando a eficiência dos processos lexicais - i.é., a leitura de palavras reais - como indicativo de leitura competente, o exame das distribuições de TR para a leitura de palavras de alta e baixa freqüência revelou que 65\% (13 de 20) dos integrantes do grupo estudado produziram uma performance eficiente na tarefa de leitura de palavras e $35 \%$ (7 de 20) dos membros remanescentes mostraram um nível de ineficiência que foi indicado por TRs (ou TRs e níveis de erros) situados fora da amplitude dos membros proficientes. Os treze bons leitores serão denominados sujeitos eficientes/competentes, e os últimos serão denominados, dependendo da extensão da ineficiência demonstrada, como casos especiais ou casos críticos. 


\section{Sujeitos Eficientes}

A porção superior esquerda da Figura 2 mostra a distribuição de tempos de reação para palavras reais e não-palavras de um leitor competente. Todos os participantes eficientes, menos um, leram os itens da lista de palavras reais correta e rapidamente, e apresentaram distribuições tipo A para esses estímulos (a exceção foi o participante VPA que produziu distribuição tipo B para as palavras de baixa freqüência: apresentou duas respostas com TRs acima de $2000 \mathrm{mseg}$ ). Embora as palavras de baixa freqüência tenham sido lidas, por todos os sujeitos,
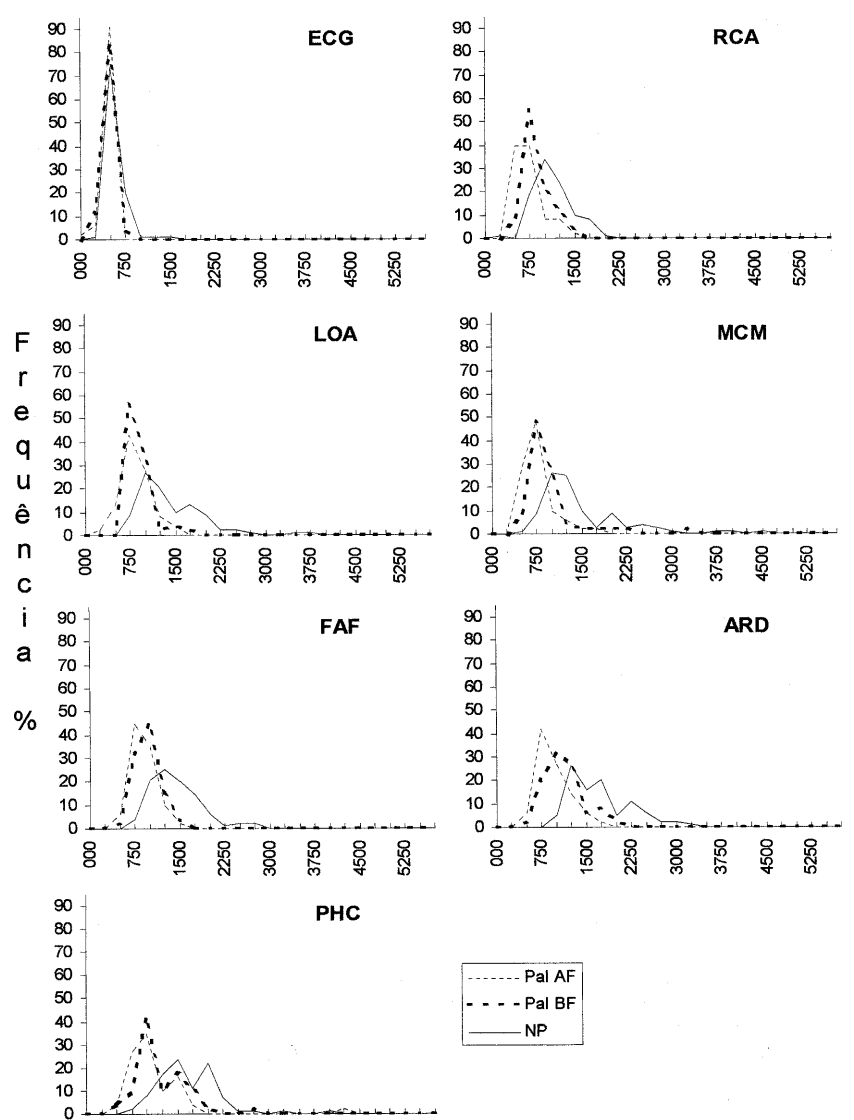

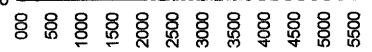

Tempo (mseg)

Figura 2. Distribuições de tempo de reação para respostas corretas para um sujeito cuja leitura é competente - ECG - e para os casos especiais e críticos do grupo estudado

com menor rapidez do que as de alta freqüência, essa diferença foi significativa somente para seis dos treze sujeitos (efeito de freqüência $=32-112 \mathrm{mseg}^{2}$, com amplitude do $t=1,881-2,796, g l=90-93, p<0,05$, ou

\footnotetext{
2 Dois leitores eficientes de palavras reais - VPA e DAM - apresentaram um efeito de freqüência fora da amplitude principal: 105 e 112 respectivamente.
}

melhor, em teste de uma cauda). Este resultado está de acordo com dados obtidos por Seymour (comunicação verbal, 31/08/1995) os quais mostram que o efeito de freqüência para tempo de processamento tende a aparecer na leitura de alguns sujeitos, mas não de todos, e que o número de sujeitos que não mostram tal efeito aumenta como resultado da idade e de experiência acadêmica. Assim, logo que as crianças ganham mais experiência em leitura, as palavras de baixa freqüência passam a ser reconhecidas com mais rapidez e mais corretamente, e o efeito de freqüência tende a diminuir.

Como esperado, a leitura da amostra não foi afetada pela irregularidade da escrita (as comparações entre palavras de alta e baixa freqüência nos três níveis de regularidade não produziram resultados significativos) $\mathrm{e}$, com relação ao efeito de comprimento, a taxa de processamento (a inclinação da regressão do tempo de reação contra o comprimento de palavras (em número de letras)) obtida para palavras de alta e baixa freqüência ficou dentro da amplitude de (-5)-57 e (-34)-66 mseg/ letra, respectivamente. Os valores negativos foram exibidos somente por dois sujeitos (um deles mostrou tal resultado na leitura de palavras de alta freqüência e o outro, na leitura de palavras de baixa freqüência) e, possivelmente, indicam uma tendência não serial na leitura de palavras.

Todos os sujeitos mostraram um efeito de lexicalidade significativo, com as não-palavras lidas mais lentamente que as palavras de baixa e de alta freqüência (amplitude do $t$ (para a diferença entre não-palavras e palavras de baixa freqüência) $=1,683-7,628, g l=126-151, p<0,05)$. A distribuição de não-palavras apresentou médias mais altas e foi mais amplamente dispersa do que a distribuição de palavras de baixa freqüência. A taxa de processamento por letra para palavras reais foi menor do que a taxa para não-palavras (amplitude de 18-71 mseg por letra). A parte $1.1 \mathrm{da}$ Tabela 1 resume os dados para palavras reais e não-palavras para os sujeitos eficientes. Apenas oito sujeitos, dos treze competentes na leitura de palavras reais, exibiram nível semelhante de competência na leitura de não-palavras.

\section{Casos Especiais e Críticos}

As partes 1.2 e 1.3 da Tabela 1 apresentam os resultados dos casos especiais e críticos respectivamente.

Leitura de palavras reais: os casos especiais e críticos exibiram distribuições de TR dentro da amplitude de 250-2000 mseg, mas com médias elevadas (p. ex.: RCA, LOA, FAF e ARD) ou distribuição do tipo A para palavras de alta freqüência e tipo $\mathrm{B}$ para palavras de baixa freqüência (p. ex.: MCM). Um membro - PHC apresentou distribuições do tipo B para palavras em 
Tabela 1. Amplitude de: (1) Média de TR, Desvio-Padrão da Distribuição de TR e Percentual de Erros para a Leitura de Palavras de Alta Freqüência, Palavras de Baixa Freqüência e Não-Palavras, (2) Efeito de Freqüência e (3) Efeito de Lexicalidade para os Sujeitos Eficientes (1.1) e para os Casos Especiais (1.2) e Críticos (1.3)

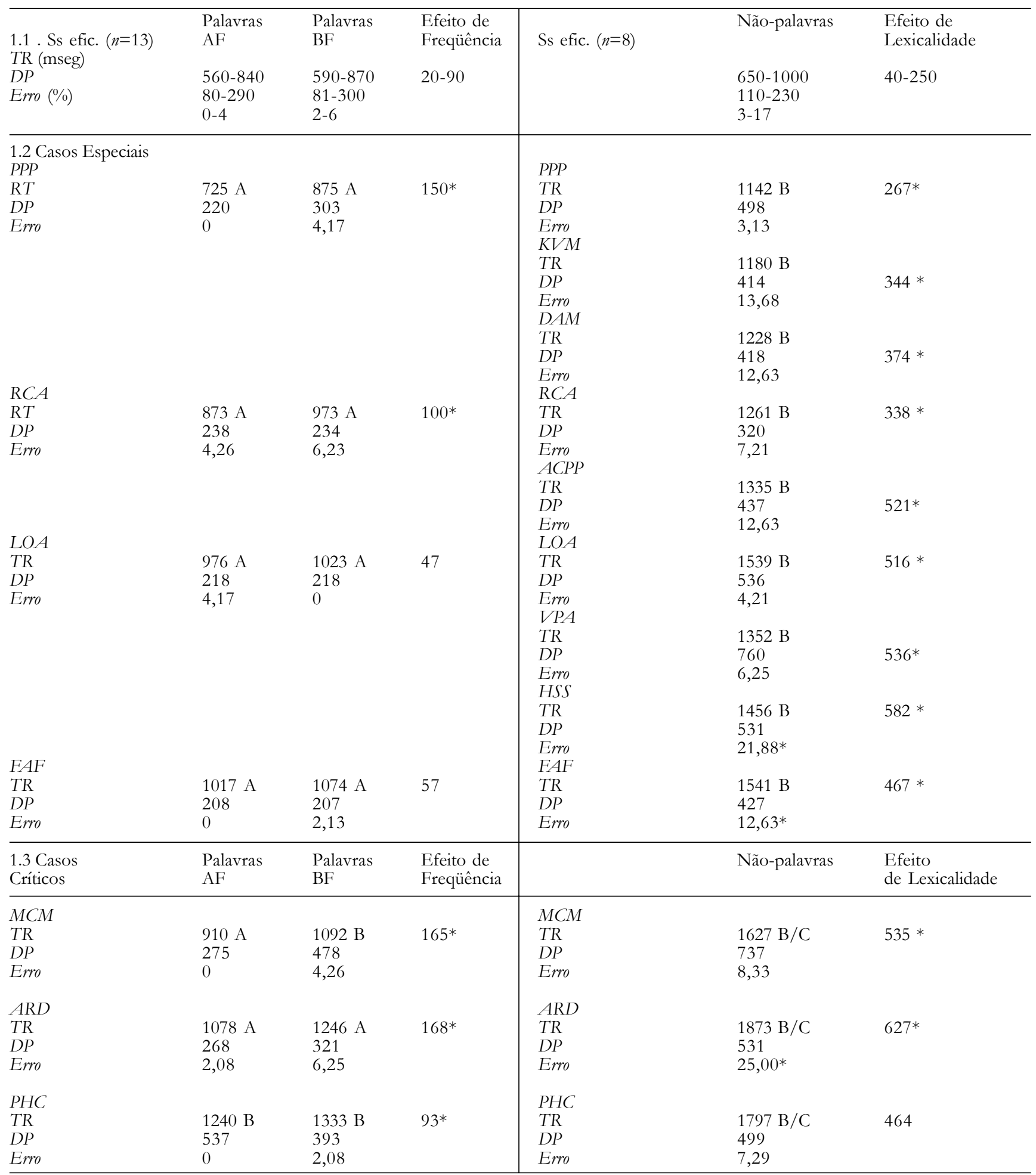

Ss efic. - Sujeitos eficientes / dp - Desvio-padrão/ Palavras AF - Palavras de alta freqüência / Palavras BF - Palavras de baixa freqüência

Em 1.1 o número 13, na porção superior esquerda, refere-se ao número de integrantes do grupo estudado (composto de 20 participantes) que produziram um desempenho eficiente na tarefa de leitura de palavras reais e o número 8 , na porção superior direita, o número de participantes - dentre os 13 competentes na leitura de palavras reais - que exibiram um nível de competência na leitura de não-palavras semelhante ao obtido na leitura de palavras reais. As letras A, B e C, o grifo e o asterisco indicam respectivamente o tipo de distribuição de tempo de reação, resultados fora da amplitude do grupo eficiente e resultados significativos.

Psicologia: Reflexão e Crítica, 2001, 14(3), pp. 537-551 
ambos os níveis de freqüência (Figura 2). A tendência para produzir, ocasionalmente, respostas lentas na leitura de palavras - efeito morfêmico - é indicativo de uma pequena deficiência na operação da rota lexical. Este efeito foi importante apenas para PHC. O efeito de freqüência foi significativo somente para quatro dos sete sujeitos (a amplitude do efeito de freqüência $=100-168 \mathrm{mseg}$, com amplitude do $t=1,823-2,796, g l=89-92, p<0,05$ ou melhor, em teste de uma cauda). Entre esses, PPP, MCM e ARD mostraram um efeito de freqüência exagerado. PHC apresentou um efeito de freqüência dentro da amplitude do grupo principal mas, como MCM e ARD, mostrou médias elevadas para palavras de alta e de baixa freqüência. $\mathrm{O}$ efeito de regularidade foi significativo para somente dois membros - RCA e PHC - e foi restrito ao tempo de processamento. A irregularidade da escrita diminuiu a leitura de palavras irregulares de baixa freqüência de RCA e PHC para 63 e $178 \mathrm{mseg}$ respectivamente $(t=2,078$ e 2,$096 ; g l=28$ e $29, p<0,05)$. Os resultados de MCM, ARD e PHC, em relação ao efeito de comprimento, mostraram taxas de processamento acima do limite superior dos participantes eficientes para ambos os níveis de freqüência de palavras.

Leitura de não-palavras: Todos os casos especiais e críticos mostraram um efeito de lexicalidade significativo (assim como os sujeitos eficientes) e apresentaram distribuições de TR do tipo B, entre esses, as distribuições de MCM, ARD e PHC tenderam para o tipo C. De acordo com a média de TR apresentada os sujeitos podem ser divididos em três categorias: casos leves, cujas médias elevadas de TR foram atribuídas ao aparecimento de algumas respostas fora da concentração principal das distribuições (p. ex. PPP e RCA); casos menos leves médias de TR dentro da amplitude de 1300-1500 (p. ex. LOA), e casos críticos - média de TR dentro da amplitude 1600-1900 (MCM, PHC e ARD). Todos os sujeitos, exceto PPP, apresentaram um efeito de lexicalidade exagerado, o que é indicativo de um efeito fonológico localizado na rota fonológica. HSS e ARD também apresentaram níveis de erros fora da amplitude do grupo principal e um efeito de lexicalidade significativo em nível de erros $(x 2=>7,385, g l=1, p<0,01)$ o que denota um grau de imprecisão no processo de tradução letra-som. Enquanto a deficiência fonológica de HSS parece estar no limite de disfunção que é compatível com os padrões normais, o maior efeito de lexicalidade exibido por ARD, combinado com um forte efeito de comprimento parece indicar um caso de dislexia fonológica.

Alguns sujeitos (incluindo PPP) mostraram uma disfunção na leitura de não-palavras que não se estendeu para a leitura de palavras reais. Para Seymour (1986), casos deste tipo ilustram uma diferenciação funcional entre as rotas lexical e fonológica e são representativos dos níveis de performance associados com um efeito fonológico suave.

\section{Distinção entre Casos Especiais e Críticos}

Seguindo o critério adotado para definir leitura competente, a principal distinção do padrão de leitura dos casos especiais e críticos foi feita com base na leitura de palavras reais, que testa a eficiência dos processos lexicais. Estes são, segundo Seymour (1986), responsáveis pela obtenção de eficiência na leitura. O padrão de leitura dos casos críticos diferiu dos casos especiais por apresentar altos tempos de reação e/ou altos efeitos de freqüência combinados com taxas de processamento por letra - efeito de comprimento - bem acima do limite superior apresentado pelos sujeitos eficientes para palavras de alta e/ou de baixa freqüência (amplitude 115-131 e 73-108 mseg para palavras de alta e baixa freqüência, respectivamente) o que, como vimos, indica processamento serial. Outra distinção entre as duas categorias de leitores ineficientes refere-se à forma como processaram as não-palavras. Enquanto os casos especiais produziram distribuições tipo B (com até sete respostas acima de $2000 \mathrm{mseg}$ ), os casos críticos apresentaram distribuições tipo $\mathrm{B}$ com forte tendência para distribuição tipo C (com 11 a 23 respostas acima de 2000 mseg). Já em relação ao efeito de comprimento para não-palavras, os dois tipos de ineficiência de leitura não são discerníveis: todos os casos especiais (exceto ACPP e FAF) e críticos mostraram valores de inclinação acima do limite superior apresentado pelos sujeitos competentes (amplitude de 94237 mseg por letra).

Em conjunto, os casos especiais e críticos apresentaram um padrão fonológico em que a leitura de não-palavras é mais fraca do que a de palavras reais. $\mathrm{O}$ efeito de lexicalidade (palavras de baixa freqüência lidas de forma significativamente mais rápida do que as nãopalavras) que foi exagerado para a maioria dos casos, variou de $267 \mathrm{mseg}$ a $627 \mathrm{mseg}(t=>4,378, g l=115-134$, $p<0,01)$. Nenhum sujeito (exceto RCA e PHC), mostrou um efeito de regularidade na leitura de palavras de baixa freqüência, mas todos produziram erros que denotam o uso de processos fonológicos. Conforme demonstrado por Seymour (1986), a deficiência neste processo nem sempre restringe o seu uso na leitura.

\section{Resumindo}

Leitura normal eficiente: como constatado por Seymour $(1986,1987)$, a leitura competente é caracterizada por uma curva de tempo de reação bem formada para 
palavras reais e não-palavras - distribuição do tipo A. As curvas para as não-palavras tendem a ter maior dispersão do que as para palavras reais. As palavras de baixa freqüência tendem a ser lidas menos rapidamente do que as palavras de alta freqüência, e este efeito de freqüência deve ser significativo para um número considerável de sujeitos. Da mesma forma, um efeito de lexicalidade em tempo de processamento (mas não em precisão) é esperado na leitura de todos os sujeitos. Contrariamente aos achados de Seymour, a irregularidade da escrita não afeta a leitura das crianças brasileiras de quarta série. As estimativas da amplitude de valores para esses dados, com base nos resultados obtidos pelos sujeitos eficientes, encontram-se resumidas em 1.1 da Tabela 1.

Limite da leitura eficiente: A inclusão dos resultados dos casos especiais (mas não dos casos críticos) nos dados dos sujeitos eficientes aumentaria a estimativa obtida, como mostra a Tabela 2. Esses números são tomados como o limite de ineficiência - efeitos morfêmico e fonológico leves - que é compatível com os padrões normais.

\section{Análise Qualitativa de Erros}

Uma vez que os erros cometidos por todos os sujeitos foram muito similares, esta análise se baseará nos erros cometidos pelos sujeitos eficientes, pelos casos especiais e críticos, como um grupo. Assim, a média quantitativa de porcentagem de erros foi 2,15 para a leitura de palavras reais, e 11,54 para a leitura de não-palavras, e já palavras reais como para não-palavras. As respostas-PRs para ambos os tipos de estímulos foram, na maioria, estruturalmente próximas aos estímulos alvo, foram da mesma natureza, parecendo imperfeições na tradução grafema-fonema ou falhas em levar em consideração as regras contextuais, mais do que um sinal de lexicalização (p. ex.: a resposta cobras para o alvo cabras, parece mais uma simples troca de vogal do que uma lexicalização). É preciso cautela, pelo menos no português, ao tentar estabelecer influências lexicais na leitura com base nas proporções de respostas gerando palavras reais. Apesar disso, a taxa consideravelmente mais alta de respostas PRs para palavras reais do que para não-palavras é indicação de uma tendência lexical na leitura de palavras.

\section{Respostas - NPs para os Itens Palavras Reais e Não- Palavras}

As respostas-NPs para palavras reais foram produzidas como resultado de regularizações, mudança da qualidade de vogal, tradução, erro contextual e de tonicidade (com predomínio dos primeiros erros). Já em resposta a não-palavras, houve predomínio de erros de tradução, de tonicidade e erros contextuais, e quase ausência de erros de regularização e de mudança da qualidade de vogal. Embora todos estes erros mostrem uma tendência fonológica, a diferença, tanto na quantidade de erros, como na ordem de freqüência de ocorrência dos tipos de erros entre respostas-NPs a palavras reais e

Tabela 2. Amplitude de: (1) Média de TR, Desvio-padrão da Distribuição de TR e Percentual de Erros para a Leitura de Palavras de Alta Freqüência, Palavras de Baixa Freqüência e Não-Palavras, (2) Efeito de Freqüência e (3) Efeito de Lexicalidade incluindo os Resultados dos Casos Especiais

\begin{tabular}{lccccc}
\hline & Palavras AF & Palavras BF & $\begin{array}{c}\text { Efeito de } \\
\text { freqüência }\end{array}$ & Não-palavras & Efeito de lexicalidade \\
\hline TR (mseg) & $840-1000$ & $870-1100$ & $47-150$ & $1100-1500$ & $250-580$ \\
$d p$ & $208-240$ & $207-300$ & & $320-760$ & \\
Erro $(\%)$ & $0-4$ & $0-6$ & $3-13$ & \\
\hline
\end{tabular}

que a mesma palavra pôde conter mais do que um erro, o número total de erros produzidos, nessa análise qualitativa, foi muito maior do que o número original (quantitativo) de erros.

\section{Respostas - PRs para os Itens Palavras Reais e Não- Palavras}

Os percentuais de respostas - PRs aos estímulos palavras reais - 42,7 - e para os estímulos não-palavras - 11,8 mostram uma preponderância de respostas-NPs tanto para a não-palavras indica uma influência lexical nas respostas dadas a palavras reais. Por exemplo, enquanto leram as não-palavras, os sujeitos cometeram mais erros de tradução e evidenciaram menos conhecimento de como o sistema de acentuação tônica funciona em português. No entanto, esta não foi a situação na leitura de palavras reais. Assim, o conhecimento do estímulo parece ajudar não só na identificação de letras, mas também na correta acentuação tônica: os estímulos familiares têm a sua representação armazenada no léxico mental. 
Regularizações e erros de mudança de qualidade de vogais não ocorreram em resposta a não-palavras, isso porque, enquanto a pronúncia de correspondências irregulares é preestabelecida nas palavras reais, esta não é a situação para as não-palavras. Por exemplo, enquanto o estímulo foxe pode ser pronunciado como /'fose/, /'fokse, ou como /'foze/, o seu contraparente - boxe - tem sua pronúncia determinada. Da mesma forma, cefo, derivado de cedo, ao contrário de cedo, pode ser corretamente pronunciado, tanto como /cefo/ ou /cEfo/. Uma nãopalavra, por não ter uma pronúncia preestabelecida, é considerada como lida corretamente quando mantém o seguinte: (1) uma correspondência permissível de letra-som num determinado contexto; (2) uma correspondência baseada em regra; (3) um padrão de acentuação tônica previsível pela ortografia do português; e, (4) a qualidade da vogal como indicado pelos diacríticos (Pinheiro, 1994). Isto significa que a comparação entre regularizações e erros de mudança de qualidade de vogais entre os dois tipos de estímulos não é esclarecedora no que se refere ao tipo de processo utilizado.

\section{Conclusão}

As respostas-PRs e as respostas-NPs para palavras reais e para não-palavras, nas três categorias de regularidade, apresentaram um nível substancial de proximidade estrutural com o estímulo-alvo e uma grande proporção de erros foi causada por pequenas imprecisões na tradução de grafema-fonema, devido à leitura incorreta de consoantes e vogais. Esses tipos de erros parecem refletir o uso de processos localizados na rota fonológica (os segmentos fonêmicos são montados segmento a segmento). Além disso, os erros causados por regularizações, mudança na qualidade da vogal e tonicidade na leitura de palavras reais são também indicações de que os sujeitos tentaram ler fazendo uso do processo de correspondência letra-som.

No entanto, a maior proporção de resposta-PRs para palavras reais do que a apresentada em resposta a nãopalavras, juntamente com a ocorrência de menos erros de tonicidade nas palavras reais, são sinais de uma influência lexical nos erros cometidos e denotam o uso de diferentes processos pelos sujeitos enquanto liam palavras reais e não-palavras: a pronúncia de uma palavra familiar, por ser recuperada como um todo, não está sujeita a erros de acentuação tônica.

\section{Discussão Geral}

O objetivo deste estudo foi explicar e ilustrar, em uma amostra com crianças brasileiras de quarta série, o
Procedimento de Avaliação Cognitiva, desenvolvido por Seymour e MacGregor (1984) e Seymour (1986, 1987) para a análise dos processos básicos de leitura, o que permite o diagnóstico das desordens que podem ser encontradas nos casos de dislexia do desenvolvimento. Com base nesse procedimento, tentou-se estabelecer um parâmetro de desempenho de leitura eficiente, que serviu de base para identificar áreas de deficiência na leitura em crianças julgadas competentes, assim como estabelecer o limite de ineficiência que é compatível com os padrões normais.

Os resultados desta investigação e de um estudo prévio (Pinheiro, 1994), têm mostrado que a teoria sobre os processos de leitura, desenvolvida no contexto da língua inglesa, pode, com poucas ressalvas - uma delas, a interpretação do efeito regularidade -, ser aplicada para explicar os processos de leitura em português. A irregularidade da escrita afeta mais a leitura competente em inglês do que em português. A implicação desta diferença para o português é que a ausência do efeito de regularidade não pode ser tomada como indicativo de uso do processo lexical (Pinheiro, 1995a).

A presente descrição da performance de leitura dos sujeitos julgados competentes reforça o achado de Seymour $(1986,1987)$, de que os leitores normais não formam um grupo homogêneo e, como conseqüência, os grupos de leitores competentes usados como controle em diferentes experimentos investigando a dislexia devem ser analisados nas mesmas bases individuais que as amostras de disléxicos. Como os leitores competentes falantes de inglês, os brasileiros mostraram deficiências localizadas e estas deficiências, apresentadas pelos casos denominados especiais, foram restritas a: (1) tempo de processamento para palavras reais e não-palavras (RCA, LOA, FAF); (2) tempo de processamento para nãopalavras apenas (PPP, KVM, DAM, ACPP e VPA); (3) tempo de processamento e precisão para não-palavras (HSS). Em termos operacionais, o padrão de leitura dos casos especiais distinguiu-se do padrão dos casos críticos pela presença, na leitura dos últimos sujeitos (ARD, MCM e PHC), de deficiências localizadas acompanhadas de indicações de processamento serial de palavras e de distribuições de tempo de reação para não-palavras aproximando-se ao tipo C.

Considerando a extensão dos danos nas rotas lexical e fonológica, todos os sujeitos apresentando áreas de deficiência exibiram um padrão fonológico predominante com a rota fonológica mais danificada do que a rota lexical. $\mathrm{O}$ extremo dessa condição foi representado por ARD cujo problema de processamento de não-palavras se estendeu à precisão, caracterizando assim um caso de 
dislexia fonológica. O seu processo fonológico mostrou-se então pior do que o lexical e esse resultado, em contraste com a de HSS, pareceu comprometer a velocidade do funcionamento da rota lexical.

Houve também sujeitos que mostraram deficiências localizadas na rota fonológica, desacompanhada de efeito na rota lexical, mas a condição reversa - rota lexical deficiente e processo fonológico eficiente - não foi encontrada. Estas condições são condizentes com a conclusão de Seymour (1987), de que imprecisão e atraso no processo fonológico não afetam necessariamente a exatidão e a velocidade de funcionamento da rota lexical e que, desde que não parece ocorrer a dissociação reversa, está implícito que o desenvolvimento do processo fonológico é, de alguma forma, dependente da eficiência do processo lexical, embora existam dados que sugerem justamente o oposto. Por exemplo, o domínio da habilidade de decodificação fonológica é visto por muitos como um pré-requisito vital para a aquisição da leitura competente e limites nessa habilidade causam dificuldades no reconhecimento de palavras novas. No início da alfabetização, a decodificação fonológica propicia a construção de unidades de reconhecimento de palavras na memória (p. ex.: Ehri, 1992; Share, 1994; Stuart \& Coltheart, 1988). Após decodificarem palavras novas algumas vezes, os leitores aprendem a reconhecer essas palavras ortograficamente, indo diretamente de sua seqüência de letras como um todo, para a sua pronúncia, sem nenhum estágio interveniente em que letras individuais são associadas a seus sons correspondentes.

Uma limitação do processamento na rota fonológica, contrariando as expectativas, não direcionou o processamento para o sistema lexical: houve, pelo contrário, sinais de uso do processo fonológico deficiente. Por exemplo, o grande efeito de freqüência e os tipos de erros cometidos na leitura de palavras reais, e a sensibilidade à variável regularidade letra-som, demonstrada por dois sujeitos, são provas de que a leitura de palavras reais recebe suporte do processo de decodificação fonológica. Além disso, Seymour (1990) afirma que todos os casos de dislexia fonológica então considerados mostraram um nível de sucesso em leitura de não-palavras, a despeito de um funcionamento lento, e anormalmente propenso a erros, do processo de conversão grafema-fonema. O caso de ARD ilustra bem esse ponto.

Com exceção de HSS e ARD, a deficiência de leitura dos casos especiais e críticos restringiu-se ao tempo de processamento. Em termos de porcentagens e de tipos de erros não houve diferença entre os leitores competentes e não-competentes. Os tipos de erros nos dois níveis de

Psicologia: Reflexão e Crítica, 2001, 14(3), pp. 537-551 competência em leitura denotaram, sobretudo, o uso do processo fonológico. Wimmer e Frith (1994) compararam a aquisição do processo de conversão letrasom em falantes de inglês e alemão e mostraram que crianças com deficiências fonológicas podem ser menos penalizadas na aquisição do processo de decodificação quando usuários de ortografias mais regulares e expostas ao método fônico. O problema de decodificação, nessas circunstâncias, pode ser bem mais atenuado e mais evidente em termos de tempo de processamento. Como o alemão, o português é bem mais regular do que o inglês e não é de surpreender que as deficiências fonológicas observadas junto a nossas crianças, como as das crianças alemãs, sejam restritas ao tempo de processamento.

No que se refere à congruência entre a avaliação das professoras e a avaliação cognitiva de leitura demonstrada, um ponto importante é que todas as crianças estudadas foram consideradas como socialmente competentes em leitura pelas suas professoras. Como podemos ver, algumas crianças mostraram deficiências localizadas, com uma delas apresentando dislexia fonológica. Como já mencionado, muitos estudos sobre a leitura normal tratam os seus resultados em termos de médias gerais, com base na pressuposição em favor da homogeneidade das funções de leitura. Como mostrado por Seymour (1986) e confirmado no presente estudo, uma metodologia que combina estudos de casos individuais com estudo de grupo tem mostrado vantagens em relação às metodologias tradicionais, que adotam um ou outro método. Variações individuais podem ocorrer tanto como resultado de diferenças de estratégias entre sujeitos, como por causa da presença de pequenas deficiências, não detectáveis por critérios formais, tais como em testes de leitura de palavras padronizados e julgamento de professores.

Por exemplo, nos estudos de 1986 e 1987 (citados anteriormente), Seymour testou uma amostra de 22 crianças de quarta série (leitoras competentes e crianças com dificuldade em leitura, selecionadas segundo o julgamento da professora). Avaliou cada criança em termos de inteligência usando uma versão abreviada do WISC-R e em leitura e escrita usando o teste Schonell Grade Word Test. O desempenho em leitura foi tomado como referência para a classificação de competência: idade de leitura igual ou mais avançada do que idade cronológica, indicativa de desempenho competente, e a idade de leitura aquém de idade cronológica, por outro lado, sinalizava desempenho não competente. Treze crianças - com idades entre 10:9 e 12:3 anos - foram classificadas como leitoras competentes por estarem, todas, adiantadas em sua idade de leitura. Apresentavam também inteligência verbal 
acima da média. Os nove sujeitos restantes - com idades entre 10:5 e 12:7 - não satisfizeram o critério estabelecido: mostraram idades de leitura aquém de suas idades cronológicas. Seis desses sujeitos apresentavam inteligência verbal média, e três, inteligência abaixo da média. Cada criança foi submetida a uma série de experimentos que incluíam, entre outras tarefas, tarefas de leitura de palavras reais e de não-palavras. Tomando os treze leitores que foram classificados como competentes, segundo o critério acima, o exame das curvas de distribuição de TR para a leitura de palavras de alta e baixa freqüência procedimento usado por Seymour para testar o funcionamento da rota lexical - mostrou que dez participantes $(77 \%$ da amostra) produziram curvas tipo A e três (23\% da amostra), curvas tipo B. Como dissemos, a tendência de, ocasionalmente, apresentar respostas lentas é tomada como indicativo de leve ineficiência na operação da rota lexical, e denota o que Seymour chama de efeito morfêmico. Os três participantes que apresentaram esse efeito - LL, KB e JS - diferiram ainda dos outros por mostrarem efeitos de freqüência exagerados. Dentre esses, KB e LL apresentaram, ainda, indícios de leitura serial expressos por taxas de processamento por letra para palavras acima da amplitude apresentada pelos sujeitos competentes. Tomando a leitura de não-palavras, teste do funcionamento da rota fonológica, os sujeitos JS e LL mostraram efeitos fonológicos bem acentuados, ambos apresentaram médias de TR acima de $2000 \mathrm{mseg}$ com distribuições contendo inúmeras respostas lentas, sendo os resultados do sujeito JS marcadamente semelhantes àqueles de crianças disléxicas que mostram um grande disfuncionamento fonológico combinado com um processamento da rota lexical parcialmente eficiente (entre os três participantes que mostram o efeito morfêmico, o efeito apresentado por JS foi mais moderado: sua leitura de palavras não mostrou sinais de leitura serial indicado por taxas de processamento por letra acima da amplitude normal).

Os resultados apresentados parecem não deixar dúvidas de que testes tradicionais de leitura de palavras, tais como o Schonell, ou mesmo o julgamento de professores sobre o desempenho de leitura de seus alunos podem falhar na identificação de deficiências mais específicas, que são detectáveis apenas mediante o uso de procedimentos baseados na aplicação das teorias e métodos da psicologia cognitiva experimental para a investigação dos processos de leitura, tais como o nível cognitivo de análise adotado por Seymour $(1986,1987)$. Por outro lado, o trabalho na área de consciência fonológica - habilidade definida como a capacidade de segmentar a fala em seus sons constituintes, e considerada como pré-requisito para o desenvolvimento da rota fonológica - tem destacado o papel do conhecimento da psicologia cognitiva no diagnóstico de deficiências fonológicas. Por exemplo, Frith (1995) explica que ter um disfuncionamento no processo fonológico significa ter alguma desordem sutil no processamento dos sons da fala, não usualmente perceptível, a não ser por profissionais bem capacitados. Indo mais além, alguns afirmam (p. ex.: Manis, Dustodio \& Szeszulski, 1993) que por ser a dislexia fonológica resultante de um profundo déficit fonológico que se manifesta - mas não exclusivamente - na leitura e na escrita, pode ser definida fora do âmbito dessas habilidades. Como conseqüência, pode existir em culturas não-letradas. Então, ao mesmo tempo em que uma dificuldade específica de leitura pode não ser detectada por meios formais, sua ocorrência pode ser prevista, independentemente de exposição ao processo de leitura. O que importa aqui é a perícia do profissional na avaliação da leitura.

Um outro ponto importante refere-se ao fato de que embora a dificuldade de leitura das crianças do presente estudo não tenha sido notada no contexto da sala de aula - alguns alunos são capazes de compensar suas dificuldades no processo de decodificação e, por isso, não demonstram suas limitações -, a leitura se tornará cada vez mais um desafio para elas. Isso nos alerta sobre a necessidade de termos um meio efetivo de monitorar o desenvolvimento de crianças e sugere que, especialmente nas séries iniciais, todos os alunos sejam avaliados na sua habilidade de leitura de palavras (variando em níveis de familiaridade) e de não palavras. Esse nível de avaliação seria então usado em conjunto com os níveis de competência - informe sobre as capacidades de leitura e de escrita de indivíduos com base em testes padronizados e $\backslash$ ou informais (na ausência de testes padronizados) e em observações de pais e professores, além de avaliação de desempenho por diferentes testes de habilidade.

Para finalizar, o trabalho de Seymour $(1986,1987)$ e a pesquisa aqui descrita demonstram que a análise da leitura no nível cognitivo consiste em uma forma direta de descrição, que é independente e não diretamente previsível, das informações contidas nas avaliações do nível de competência (testes tradicionais de leitura e informações de professores). As descrições sobre a habilidade de leitura, geradas dessa última abordagem, embora fundamentais, não oferecem, por si só, uma base adequada para uma análise funcional dos processos comprometidos e nem sobre a extensão desse comprometimento. Conclui-se, então, que uma avaliação satisfatória da leitura deve ser conduzida no nível de competência e no nível cognitivo (além do nível 
biológico - índice das funções cerebrais e sensoriais - usadas em casos de dislexia).

A análise aqui relatada não apenas mostra a amplitude dos procedimentos de avaliação desenvolvidos por Seymour $(1986,1987)$ - eles podem satisfatoriamente ser usados para avaliar a performance de leitura de crianças que falam inglês e português (além de outras línguas) - mas também ilustram o grande potencial destes procedimentos para uso de pesquisadores e profissionais. Uma implicação prática do uso desse procedimento é que ele pode levar a uma melhora das possibilidades de reeducação.

A partir desse trabalho e de outros, Pinheiro (2000) desenvolveu um instrumento de avaliação cognitiva das capacidades de leitura e da escrita, denominado AVACLE, que consiste em tarefas de leitura em voz alta e de tomada de ditado de listas de palavra reais e de não-palavras isoladas, além de tarefas de decisão lexical e semântica. Todos os estímulos serão apresentados na tela de um computador, comandado por um programa - $\mathrm{Mel}$ Professional - que marca o tempo de reação das respostas, sua precisão e, ao fim da prova, apresenta a análise estatística dos resultados. Para sua validação, esse instrumento será aplicado em amostras de crianças mineiras da primeira à quarta série do Ensino Fundamental com o objetivo de se criarem tabelas normativas para essa população (pesquisa em andamento, Pinheiro \& Bellico da Costa, 2000). Essa avaliação - apropriada apenas para a investigação de indivíduos que já adquiriram alguma competência em leitura - deve ser complementada com medidas de consciência fonológica e de leitura em contexto.

\section{Referências}

Capovilla, A. G. S., Capovilla, F. C. \& Macedo, E. C. (1998). Validação do software CronoFonos para a análise de tempo de reação, duração e freqüência de segmentação locucionais na leitura em voz alta de itens isolados. Ciência Cognitiva: Teoria, Pesquisa e Aplicaşão, 2(3), 253340.

Ehri, L. C. (1992). Reconceptualizing the development of sight word reading and its relationship to recoding. Em P. B. Gough, L. C. Ehri \& R. Treiman (Orgs.), Reading acquisition (pp. 107-144). Hillsdale: Lawrence Erlbaum.

Ellis, A. \& Young, A. W. (1988). Human cognitive neuropsychology. London: Lawrence Erlbaum.

Frith, U. (1995). Dyslexia: can we have a have a shared theoretical framework. Educational and Child Psychology, 12(1), 6-17.
Manis, F. R., Dustodio, R. \& Szeszulski, P. A. (1993). Development of phonological and orthographic skill: a 2-year longitudinal study of dyslexic children. Journal of Experimental Psychology, 56, 64-86.

Morton, J. (1979). Facilitation in word recognition: Experiments causing change in the logogen model. Em P. A. Kolers, M. E. Wrolstad \& H. Bouma (Orgs.), Processing of visible language 1 (pp. 259-268). New York: Plenum Press.

Pinheiro, A. M. V. (1994). Leitura e escrita: Uma abordagem cognitiva. Campinas: Editorial Psy.

Pinheiro, A. M. V. (1995a). Reading and spelling development in Brazilian Portuguese. Reading \& Writing, 7(1), 111-138.

Pinheiro, A. M. V. (1995b). Dificuldades específicas de leitura: a identificação de déficits cognitivos e a abordagem do processamento de informação. Psicologia: Teoria e Pesquisa, 11, 107-115.

Pinheiro, A. M. V. (1999). Cognitive assessment of competent and impaired reading in Scottish and Brazilian children. Reading \& Writing, 11, 175211.

Pinheiro, A. M. V (2000, Junho). Instrumento computadorizado de avaliação cognitiva dos processos de leitura em crianças. Trabalho apresentado no I Simpósio de Informática Educativa da Universidade Federal de Juiz de Fora, MG.

Pinheiro, A. M. V. \& Bellico da Costa, A. E. (2000). Avaliação cognitiva das capacidades de leitura e de escrita de crianças no ensino fundamental - AVACLE. Projeto de pesquisa. Curso de Psicologia, Universidade Federal de Minas Gerais. Belo Horizonte, MG.

Pinheiro, A. M. V. \& Keys, K. J. (1987). A word frequency count in Brazilian Portuguese. Manuscrito não publicado. Curso de Psicologia, Universidade Federal de Minas Gerais. Belo Horizonte, MG.

Pinheiro, A. M. V. \& Parente, M. A. M. P. (1999). Estudo de caso de um paciente com dislexia periférica e as implicações dessa condição nos processamentos centrais. Pró-fono: Revista de Atualização Científica, 11(1), 115-123.

Schonell, G. B. \& Schonell, F. E. (1956). Diagnostic and attainment testing. Edinburgh: Oliver \& Boyd.

Seymour, P. H. K. (1986). Cognitive analysis of dyslexia. London: Routledge \& Kegan Paul.

Seymour, P. H. K. (1987). Individual cognitive analysis of competent and impaired reading. British Journal of Psychology, 78, 483-506.

Seymour, P. H. K. (1990). Developmental dyslexia. Em M. W. Eysenck (Orgs.), Cognitive psychology: An international review (pp. 136-196). London: John Wiley.

Seymour, P. H. K. (1994).Variability in dyslexia. Em C. Hulme \& M. Snowling (Orgs.), Reading development and dyslexia (pp. 65-85). London: Whurr.

Seymour, P. H. K. \& MacGregor, C. J. (1984). Developmental dyslexia: A cognitive experimental analysis of phonological, morphemic and visual impairments. Cognitive Neuropsychology, 1, 43-82.

Share, D. L. (1994). Phonological recoding and self-teaching: Sine qua non of reading acquisition. Cognition, 55, 151-218.

Stuart, K. M. \& Coltheart, M. (1998). Does reading develop in a sequence of stages? Cognition, 30, 139-181.

Wimmer, H. \& Frith, U. (1994). Reading difficulties among English and German children: Same cause - different manifestation. Proceedings of the Workshop on Context of Literacy (Vol. III, pp. 21-24). Nice, França.

Recebido: 28/08/2000

Revisado: 13/02/2001 Aceite Final: 08/05/2001

Sobre a autora

Ângela Maria Vieira Pinheiro é Psicóloga, Pesquisadora da FAPEMIG, Doutora em Psicologia pela Universidade de Dundee, Escócia, UK, Professora do Curso de Psicologia da UFMG. 